\title{
The ride comfort $v s$. handling compromise for off-road vehicles
}

\author{
P.S. Els *, N.J. Theron, P.E. Uys, M.J. Thoresson \\ Department of Mechanical and Aeronautical Engineering, University of Pretoria, Pretoria 0002, South Africa
}

\begin{abstract}
When designing vehicle suspension systems, it is well-known that spring and damper characteristics required for good handling on a vehicle are not the same as those required for good ride comfort. Any choice of spring and damper characteristic is therefore necessarily a compromise between ride comfort and handling. The compromise is more pronounced on off-road vehicles, as they require good ride comfort over rough off-road terrain, as well as acceptable on-road handling. In this paper, the ride comfort $v s$. handling compromise for off-road vehicles is investigated by means of three case studies. All three case studies indicate that the spring and damper charcteristics required for ride comfort and handling lie on opposite extremes of the design space. Design criteria for a semi-active suspension system, that could significantly reduce, or even eliminate the ride comfort $v s$. handling compromise, are proposed. The system should be capable of switching safely and predictably between a stiff spring and high damping mode (for handling) as well as a soft spring and low damping mode (for ride comfort). A possible solution to the compromise, in the form of a four state, semi-active hydropneumatic spring-damper system, is proposed.
\end{abstract}

Keywords: Ride comfort; Handling; Suspension design; Off-road; Vehicle; Semi-active

\section{Background}

The principal aim of a vehicle's suspension system is to isolate the occupants from external terrain induced disturbances, while still allowing the average driver to maintain control over the vehicle and drive it safely. It is commonly accepted that vehicles with soft suspension systems generally provide very good ride comfort at the expense of handling. Most sports cars suffer from the opposite symptoms in that a firm suspension system offers excellent handling up to very high speeds but the ride comfort is often described as harsh or rough.

This becomes more pronounced when the operational requirements of a vehicle are in conflict with the suspension design. On most off-road vehicles, high ground clearance is required to enable crossing obstacles. Large suspension travel is also required to keep all wheels in contact with the

\footnotetext{
* Corresponding author. Tel.: +27 12420 2045; fax: +27 123265087.

E-mail addresses: schalk.els@eng.up.ac.za (P.S. Els), nico.theron@ up.ac.za (N.J. Theron), petro.uys@up.ac.za (P.E. Uys).
}

ground in order to maintain traction. Even load distribution amongst the different wheels improves traction, but requires soft springs. A problem however arises when these vehicles have to be operated at high speeds on smooth roads. The high centre of gravity, large suspension travel and soft springs create an inherent handling and stability problem making these vehicles prone to rollover.

The purpose of this paper is to investigate the suspension requirements for good ride comfort and good handling, respectively. Only the effect of changes in spring and damper characteristics, and not suspension kinematics, is analysed. The focus is on vehicles that require both good on-road handling as well as good off-road ride comfort. This class of vehicle includes military vehicles as well as sports utility vehicles (SUV's).

\section{Ride comfort}

Four methods to objectively evaluate ride comfort (also referred to as human response to vibration) are used throughout the world today. The ISO 2631 standard [1] 
is used mainly in Europe and the British standard BS 6841 [2] in the United Kingdom. Germany and Austria use VDI 2057 [3], while average absorbed power or AAP [4] is used by the United States of America and by NATO in the NATO reference mobility model (NRMM). This presents two questions namely: (i) which method is most suitable for the evaluation of off-road vehicle ride comfort, and (ii) how do the results differ if different methods are used.

Els [5] investigated the correlation between objective methods for the determination of ride comfort and subjective comments from passengers driving in vehicles. For objective measurements, the ISO 2631, BS 6841, AAP and VDI 2057 methods were used. The emphasis was on the ride comfort of military vehicles operated under off-road conditions over typical terrains. Els devised an exper-iment in which a 14-ton, $4 \times 4$ mine protected military vehi-cle (similar to the vehicle indicated in Fig. 1) was driven over seven different terrains, using various vehicle speeds and tyre pressures. The terrains were chosen to be representative of typical operating conditions in Southern Africa and excite significant amounts of body roll, pitch and yaw motion. Seven groups, consisting of nine passengers each, were used for determining subjective comments using a questionnaire, while simultaneously recording accelera-tion data required for objective analysis at 11 positions in the vehicle.

The resulting measured data sets were converted into objective ride comfort values according to the ISO 2631, BS 6841, AAP and VDI 2057 methods. The unweighted values were also used for comparative purposes. Objective values were calculated for all the relevant parameters and measurement positions and compared to subjective ratings.

It is concluded by Els [5] that any of the four methods under consideration, namely ISO 2631, BS 6841, AAP and VDI 2057, could be used to objectively determine ride comfort for the vehicles and terrains of importance for the study. The vertical acceleration measurements give the best, and in fact the only reliable subjective-objective correlation and should be used in all cases. The RMS values are sufficient for ISO 2631, BS 6841 and unweighted values. Correlation for roll, pitch and yaw acceleration with subjective values is poor and not useful.

According to Murphy [6], a 6-W AAP limit is normally assumed to be sustainable, while values as high as $12 \mathrm{~W}$ can be sustained only for a short period of time. It was found by Els [5] that the $6 \mathrm{~W}$ AAP limit correlated with a value of $50 \%$ on the subjective response scale. Els reports that the limits for the other methods, corresponding to the $50 \%$ subjective rating, are $2.0 \mathrm{~m} / \mathrm{s}^{2}$ RMS (according to ISO 2631 - rated as "very uncomfortable" according to Table 9 and Annex C in [1]), $2.8 \mathrm{~m} / \mathrm{s}^{2}$ for the unweighted RMS values, $1.8 \mathrm{~m} / \mathrm{s}^{2} \mathrm{RMS}$ for BS 6841, a VDI 2057 value of 88 and a 4$\mathrm{h}$ vibration dose value (VDV) of $26 \mathrm{~m} / \mathrm{s}^{1.75}$ were also found. The $4-h$ VDV of $26 \mathrm{~m} / \mathrm{s}^{1.75}$ is significantly higher than the VDV of 15 normally assumed to be the guideline.

\section{Handling}

Harty [7] defines handling as the percentage of the available friction or the maximum achievable lateral acceleration utilised by the vehicle-driver combination. At values lower than the linearity limit, the vehicle acts in a linear fashion e.g. a given steering input results in a certain vehicle response. Increasing the steering input results in a similar increase in vehicle response and everybody can control the vehicle and avoid accidents. At values higher than the friction limit, control over the vehicle is physically impossi-

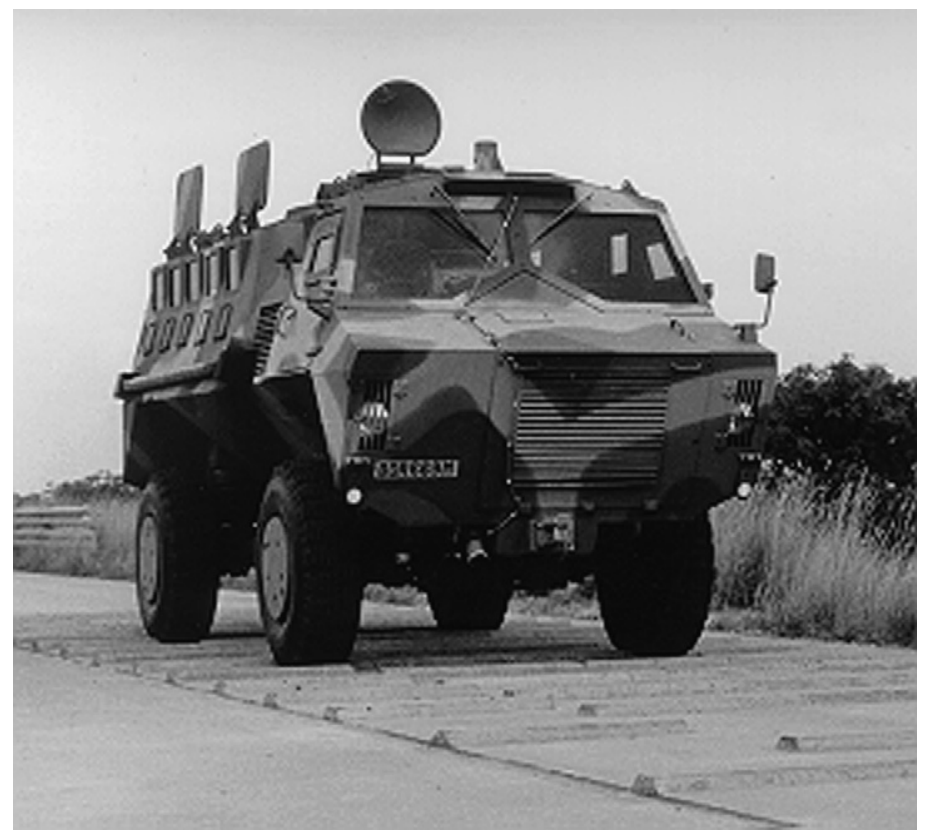

Fig. 1. Photograph of vehicle used in case study 1. 
ble and even the most experienced driver in the best handling vehicle will lose control. Harty sees the task of the vehicle designer as having two aims namely: to raise the absolute friction limit and to raise the linearity limit.

While human response to vibration (ride comfort) has been extensively researched, a single, unambiguous objective criterion for handling has eluded the vehicle science community despite numerous studies pertaining to the topic. For this reason a study was performed by Uys et al. [8] in order to establish relationships that can be used to objectively quantify vehicle handling. They tried to identify parameters that can be used to characterise handling and that can be used as the objective function in suspension optimisation studies. Test results for three different vehicles and four different drivers were analysed.

It was apparent from a literature survey on the topic that measurement of vehicle handling is not clear-cut. No unambiguous metric for handling is apparent. There are, however, some parameters that are worth considering and these were used to direct an experimental investigation.

Handling tests can be divided into two main categories namely steady state handling tests and dynamic handling tests (also called transient response tests).

The most widely used steady state handling test is the constant radius test, where the vehicle is driven around a circle with constant radius (e.g. a dry skid pan). The most important parameters that need to be measured are steering wheel angle and lateral acceleration. The test starts at the lowest speed the vehicle can drive smoothly. Speed is gradually increased until the constant radius cannot be safely maintained. A graph of lateral acceleration against vehicle speed is used to determine whether the vehicle exhibits oversteer (negative gradient), understeer (positive gradient) or neutral steer (zero gradient) behaviour [9]. Variations on this test method are the constant steering angle test (where speed and radius changes) and the constant speed test (where steering angle and radius changes).

Dynamic handling tests can be either closed loop where a human driver tries to steer the vehicle through a prescribed path, or open loop where the steering angle $v s$. time is prescribed. Closed loop tests include the severe double lane change test (ISO 3888-1, [10]), obstacle avoidance test (ISO 3888-2, [11]) and "Moose" or "Elk" test [12]. Open loop tests can be performed either by an experienced test driver or a computer controlled steering robot. These include the J-turn [13], Fishhook [13], step steer and pulse steer tests [14].

In previous simulation studies by Els and Uys [15], i t was shown that measurements of roll angle could be used for optimisation of suspension settings. Choi et al. [16], Data and Frigero [17] and Crolla et al. [18] also refer to roll angle as a measure of handling, as does the NHTSA survey [19] and Vlk [20].

An experiment was designed by Uys et al. [8], in which three vehicles were test driven by four drivers on two handling test tracks. The test results strongly suggest that roll angle is a suitable metric to measure handling.

\section{Ride comfort vs. handling}

According to Harty [21], ride comfort, handling and stability are to some extent in conflict with each other. Using controllable suspension systems can reduce this conflict. It is also important that controllable systems give the maximum benefit for the smallest possible actuation forces or energy requirements.

Karnopp [22] states that for ride comfort, the suspension should isolate the body from high frequency road inputs. At lower frequencies the body and wheel should closely follow the vertical inputs from the road to improve handling. Resonance of the body and wheels should be controlled, so that these disturbances are not excessively amplified and so that wheel hop and loss of wheel contact with the ground can be avoided. The suspension must also control forces due to change in payload, forces from braking and cornering and aerodynamic forces. All these requirements are difficult, and even impossible to meet with a passive suspension system.

Holdman and Holle [23] investigate the possibilities to improve ride comfort and handling of a 3.5-ton delivery vehicle. They illustrate that a passive system will always be a compromise between comfort and safety. They use three different damping curves namely soft (2/3 of standard), standard and hard (1.5 times standard) in an attempt to improve ride comfort. Different damping sys-tems have a small effect on lateral dynamics (handling). Additional forces need to be applied between the body and the wheel as a function of lateral acceleration to reduce body roll angle.

Karnopp and Margolis [24] discuss the effects of a change in spring and damper rates on the transfer function of a single degree of freedom suspension system. It is said that changing the damping alone is not a very efficient way of stiffening or softening a suspension system. Changing the spring stiffness changes the natural frequency of the system but the asymptotic attenuation at higher frequencies stays the same. The study concludes that a system containing variable spring and damper rates can be very advantageous in improving ride comfort.

A vehicle suspension system must be designed to provide adequate damping over a range of driving conditions e.g. smooth and rough roads, laden and unladen conditions as well as good ride comfort and handling according to Hine and Pearce [25]. This leads to the well-known conflict between the maximum use of suspension working space for best ride comfort (e.g. soft spring with large travel) and the need to provide sufficient displacement for all road conditions and road surfaces (e.g. preventing bumpstop contact on rough roads). Their proposed solution is a two- or threestate semi-active damper with ride height control.

Wallentowitz and Holdman [26], Ikenaga et al. [27] and Nell [28] also agree that suspension design involves a compromise between ride comfort and handling.

The three case studies that will be presented now analyses the spring and damper characteristics required for opti- 
mum ride comfort and handling as applicable to off-road vehicles.

\section{Case study 1: landmine protected vehicle}

Els and Van Niekerk [29] perform an evaluation of the ride comfort and handling of a heavy off-road military vehicle using DADS (dynamic analysis and design system) software. The vehicle used for simulation is a 12-ton $4 \times 4$ military vehicle, designed for off-road use over very rough terrain. The vehicle is fitted with $14.00 \mathrm{R} 20$ off-road tyres. A photograph of the vehicle is shown in Fig. 1.

The three-dimensional, multiple degree of freedom, nonlinear DADS simulation model consists of 11 rigid bodies (vehicle body, four wheels, front axle, rear axle, ground, two front hubs and steering pivot). The wheels and hubs are connected to the axles using seven revolute joints, while axle locating rods and steering links are modelled using 10 spherical-spherical joints. Force elements consist of nonlinear dampers, springs (linear and hydropneumatic, depending on simulation), bump stops, as well as a generic non-linear tyre model.

The resulting model has 66 degrees of freedom but after adding joints, constraints and a driver model, 14 unconstrained degrees of freedom remain. These consist of the vehicle body displacements (lateral, longitudinal, vertical, roll, pitch and yaw), wheels (rotation), front axle (vertical, roll) and rear axle (vertical, roll). Non-linear spring, damper, bump-stop and tyre characteristics are used. The vehicle is steered over a predetermined course by a simple driver model that estimates the lateral position error based on the yaw angle of the vehicle body at the current time step and the desired lateral position at the driver preview time of $0.6 \mathrm{~s}$. The driver model is implemented using control elements in DADS such as amplifiers, summers and inputs.

Simulation was performed with different spring and damper characteristics in order to complete a sensitivity analysis. A severe double lane change manoeuvre, performed over Belgian paving [30] (also see Fig. 13) a t a vehicle speed of $60 \mathrm{~km} / \mathrm{h}$, was chosen as representative of high speed off-road driving on gravel roads and tracks. A displacement spectral density of the Belgian paving used in the simulation is given in Fig. 2. The speed of $60 \mathrm{~km} / \mathrm{h}$ is close to the maximum double lane change speed achievable with the particular vehicle on a level paved surface.

As the simulation included ride comfort, stability and handling, interpretation of the results is difficult and it is necessary to define certain performance criteria. For ride comfort, the vertical acceleration at the vehicle body's centre of gravity was filtered using the BS $6841 \mathrm{~W}_{\mathrm{b}}$ filter [2] and the RMS value determined. Motion sickness dose values were determined in a similar fashion using the motion sickness or $\mathrm{W}_{\mathrm{f}}$ filter. When driving in off-road conditions, body roll and pitch usually give the first indication that the vehicle speed is excessive. Furthermore, it is more difficult to brace the human body against roll and pitch motion than is the case for yaw or vertical motion. Stability and handling were therefore evaluated using the RMS roll angle, RMS roll velocity and RMS pitch velocity of the vehicle body.

Two suspension configurations were simulated namely linear springs as well as non-linear hydropneumatic springs. In both cases, the damper force ratios (damper force divided by the baseline damper force at any specific damper speed) were varied between 0.001 and 3. For both linear and hydropneumatic springs, nine different spring and 12 different damper characteristics were simulated, giving a total of 108 simulation runs. The simulation results are presented as 3-dimensional surface plots (Figs. 3-5) where the various ride comfort and handling parameters are plotted against the damper force ratio and the natural frequency (or stiffness) of the suspension system. The graphs represent the percentage reduction in the respective values

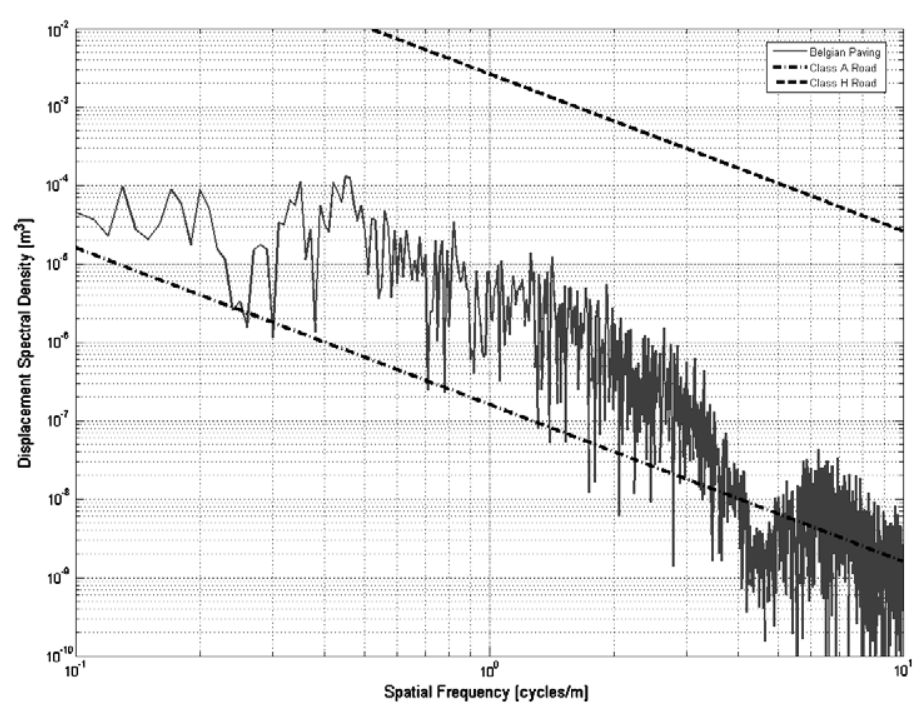

Fig. 2. Displacement spectral density of Belgian paving. 

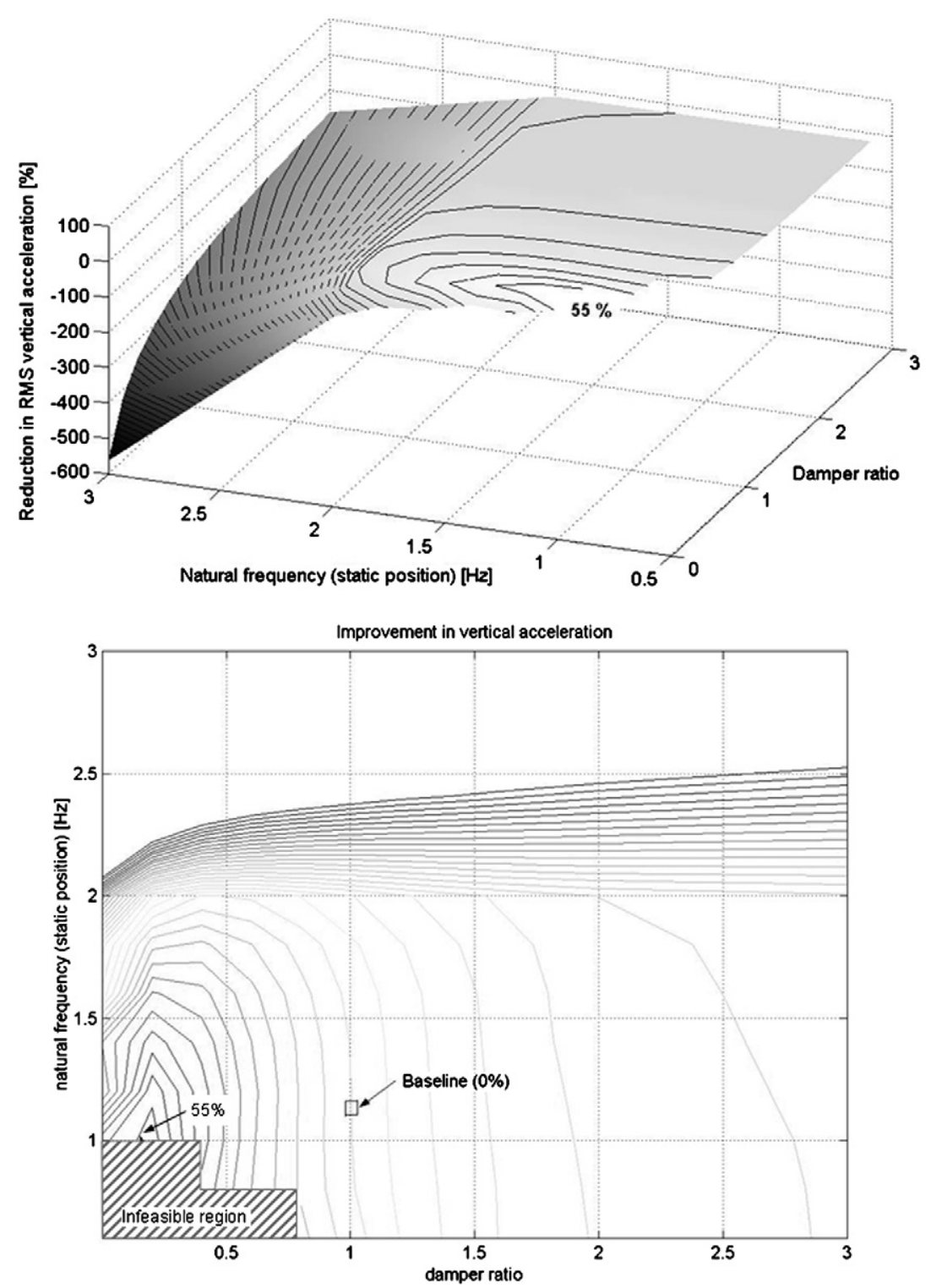

Fig. 3. Reduction in weighted RMS vertical acceleration (ride comfort - linear spring).

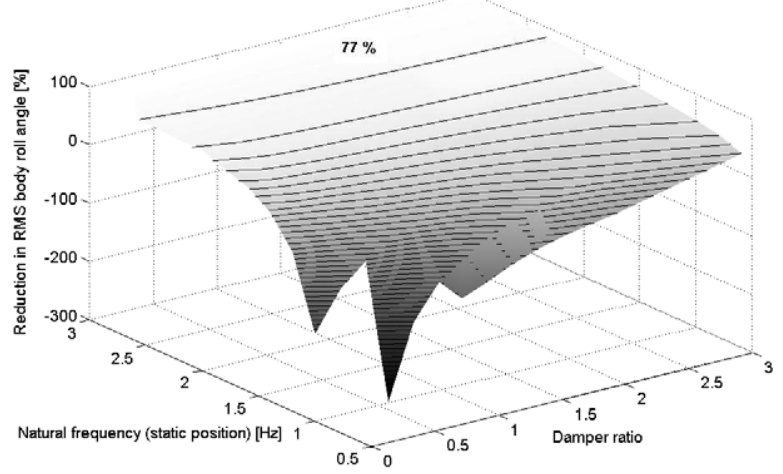

Fig. 4. Reduction in roll angle (linear spring).

relative to that of the baseline suspension (damper force ratio of 1 and natural frequency of $1.2 \mathrm{~Hz}$ ). The bot-tom corners of the graphs (low spring and damper rates)

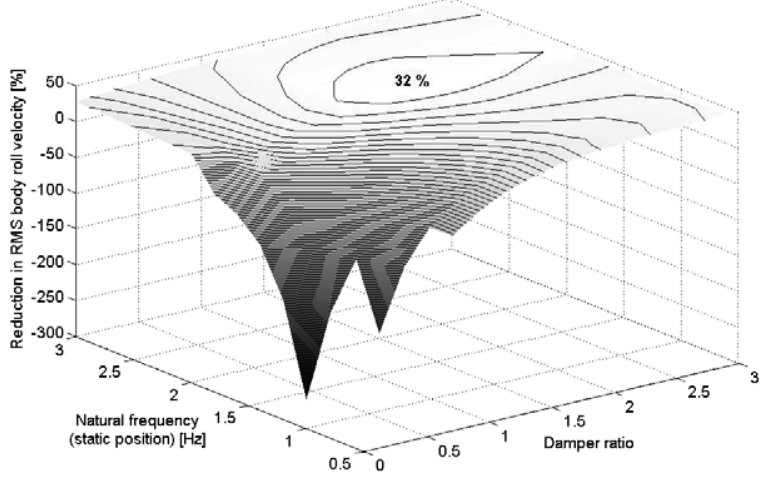

Fig. 5. Reduction in roll velocity (linear spring).

contain no data, since the suspension is so soft that the vehicle could not perform the double lane change manoeuvre and rollover occurred (see bottom part of Fig. 3 for the 
infeasible region). Figs. 3-5 represent the results for the linear springs.

Fig. 3 indicates the relationship between natural frequency (spring stiffness) and damper force ratio on the ride comfort for the linear spring configuration. A maximum reduction of $55 \%$ is reached at a natural frequency of $1 \mathrm{~Hz}$ and damper force ratio of 0.2 . The figure also indi-cates that ride comfort can be $600 \%$ worse by using a stiff spring with low damping. The percentage reduction is calculated as follows

$\%$ reduction $=\frac{(\text { baseline value }- \text { new value })}{\text { baseline value }} * 100$.

The trend indicates that further improvements in ride comfort may be possible at lower natural frequencies, but that the vehicle becomes unstable and rolls due to the handling manoeuvre. The best spring characteristic for ride comfort is therefore as low as can be tolerated from a stability and handling perspective. Although a reduction in damper force ratio improves ride comfort, a certain minimum damping level is required to prevent rollover.

A maximum reduction of $51 \%$ in the motion sickness dose value (not indicated) was achieved for the lowest natural frequency and highest damper force ratio. The motion sickness dose value was however much less sensitive to the damping value than to the natural frequency. It was expected that the motion sickness dose value should increase with a reduction in suspension natural frequency, but apparently this is offset by the improved isolation performance of the lower natural frequency suspension.

A maximum reduction of $77 \%$ in roll angle (Fig. 4) was achieved at a suspension natural frequency of $3 \mathrm{~Hz}$. This comes at the expense of ride comfort that is reduced by between $200 \%$ and $600 \%$ depending on the damping (see Fig. 3 ). With this very stiff spring, the roll angle reduction is insensitive to the damper force ratio as can be expected. The optimal characteristics for roll velocity (reduction of $32 \%$ ) are achieved at a suspension natural frequency of $2 \mathrm{~Hz}$ and damper force ratio of 1.8 (see Fig. 5). Both roll angle and roll velocity are therefore reduced by higher spring and damper characteristics although the trends indicate that there is little improvement after the spring and damper characteristics have been doubled from the base-line values. Because the springs and tyres act in series, their deflections are influenced by their relative stiffness, e.g. if the spring stiffness increases, while the tyre stiffness remains constant, spring deflection will decrease at the expense of increased tyre deflection.

All the graphs shown are for the linear suspension configuration mainly due to the wider range of suspension natural frequencies that could be indicated. All the tendencies are however similar for the hydropneumatic suspension system. The damper characteristics are the same for both the linear and hydropneumatic suspensions, but the spring force for the hydropneumatic suspension increases gradually with increased suspension deflection.
The expected conclusion is made that ride comfort requires opposite characteristics to handling and stability. The suspension resulting in the best ride comfort, leads to rollover. This fact gives a good motivation for the use of a semi-active spring-damper system to improve both ride comfort and handling. The semi-active spring-damper system has to be designed with sprung mass natural frequencies of approximately 0.6 and $2 \mathrm{~Hz}$, and damper force ratios of $0.2-0.5$ and 2.0 . The results are only valid when the terrain inputs do not result in contact with the bumpstops. When bump-stop contact occurs over rougher terrain, a stiffer suspension may result in improved ride comfort.

Although the simulation results indicate optimal values for the spring and damper characteristics, these characteristics may not always be obtainable on a practical vehicle suspension system because of physical constraints such as space required by large accumulators, or damper characteristics that will result in cavitation inside the damper.

The maximum rebound damper force is limited by the pressure difference across the damper. When the pressure difference becomes so large that the pressure in the hydraulic strut approaches zero, then cavitation will occur. The oil will boil and apart from the physical damage that may result, the damper force will stay constant. The minimum damper characteristic on the other hand is limited by the flow loss through the channels and hydraulic valves.

In order to obtain a sprung mass natural frequency of $3 \mathrm{~Hz}$ for the vehicle, a basic $1 / 4$ car analysis indicates that the spring stiffness must be four times higher than the tyre stiffness, while the static deflection of the spring is only $5.5 \mathrm{~mm}$. This implies that the tyre will deflect significantly, negating the effect of the stiff spring. On the other hand, the static deflection of $0.668 \mathrm{~m}$, required for a $0.6 \mathrm{~Hz}$ natural frequency, is also unreasonable.

Similar limitations are applicable to the hydropneumatic spring except that the spring stiffness used for calculation of the natural frequency is linearised through the static suspension position. The accumulator of 2 or 31 capacity, required for the soft spring characteristic, is bulky and it is doubtful whether this will fit into the space envelope normally available on a vehicle.

The results indicated that for best ride comfort, the damper force ratio should be between $20 \%$ and $50 \%$ of the baseline value and the natural frequency should be in the region of $0.6 \mathrm{~Hz}$. For optimal stability and handling, the natural frequency should be around $2 \mathrm{~Hz}$ and the damper force ratio double the baseline value. It should however be noted that these values may differ for other vehicle speeds, terrain inputs or handling manoeuvres. The values might also be vehicle-specific.

\section{Case study 2: Land Rover Defender 110}

Many sport utility vehicles suffer from the same ride comfort vs. handling compromise as military vehicles. In order to simulate the ride comfort and handling of the 
Land Rover Defender vehicle, a first order DADS simulation model, based on a combination of measured and estimated parameters for a Land Rover Defender 110 sports utility vehicle (see Fig. 6), was developed. A second, more detailed model was later developed and is discussed in Section 7.

The DADS model has 81 degrees of freedom, but after adding joints, constraints and a driver model, 14 unconstrained degrees of freedom remain. These consist of the vehicle body displacements (lateral, longitudinal, vertical, roll, pitch and yaw), wheel rotations, front axle vertical displacement and roll and rear axle vertical displacement and roll. Non-linear spring, damper, bump-stop and tyre characteristics are used. The vehicle is steered over a predetermined course by a simple driver model which estimates the lateral positional error based on the yaw angle of the vehicle body at the current time step and the desired lateral position at a specified driver preview time. The driver model is implemented using amplifiers, summers and input elements.

The coil springs on the baseline suspension were replaced with hydropneumatic springs where the spring stiffness is determined by the gas volume in the static position. Static gas volumes were varied between 0.01 and 3.01 . This gives a range of spring stiffness from about 10 to 0.1 times that of the baseline coil spring stiffness. To simplify the damper characteristics, the baseline damper force was scaled with a constant factor that varied between 0.5 (i.e., softer than baseline) and 3 (three times higher than baseline). Simulations were performed for seven damper characteristics and 10 spring characteristics within these ranges, giving a total of 70 simulation runs.

Ride comfort was simulated over the same Belgian paving course as described in Section 5 at a vehicle speed of 60 $\mathrm{km} / \mathrm{h}$. Ride comfort was evaluated using the vertical acceleration at the driver position (right front) as well as the left rear passenger position. The vertical acceleration was weighted using the British standard $\mathrm{BS} 6841 \mathrm{~W}_{\mathrm{b}}$ weighting filter and calculating a weighted root mean square (RMS) value. A three-dimensional plot of weighted RMS acceleration vs. spring static gas volume and damper scale factor, for the driver's seat position, is indicated in Fig. 7. The lowest acceleration levels (best ride comfort) are obtained with low damping (damper scale factor of 0.8 ) and soft springs (static gas volume $>0.51$ ). Motion sickness values do however increase with very soft springs (not shown).

Handling was simulated by performing a severe double lane change manoeuvre at a speed of $60 \mathrm{~km} / \mathrm{h}$ for the same values of spring and damper characteristics used for ride comfort analysis. Maximum body roll angle was used as the evaluation parameter of handling. The smallest body
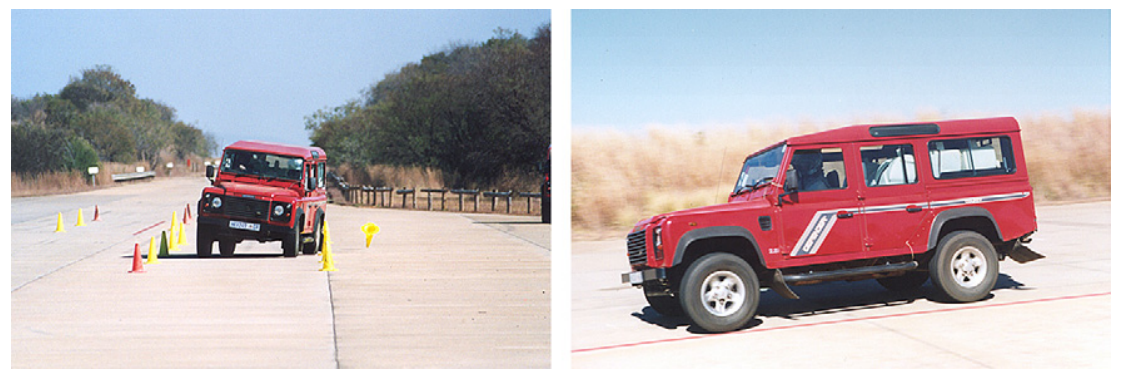

Fig. 6. Land Rover Defender 110 vehicle.

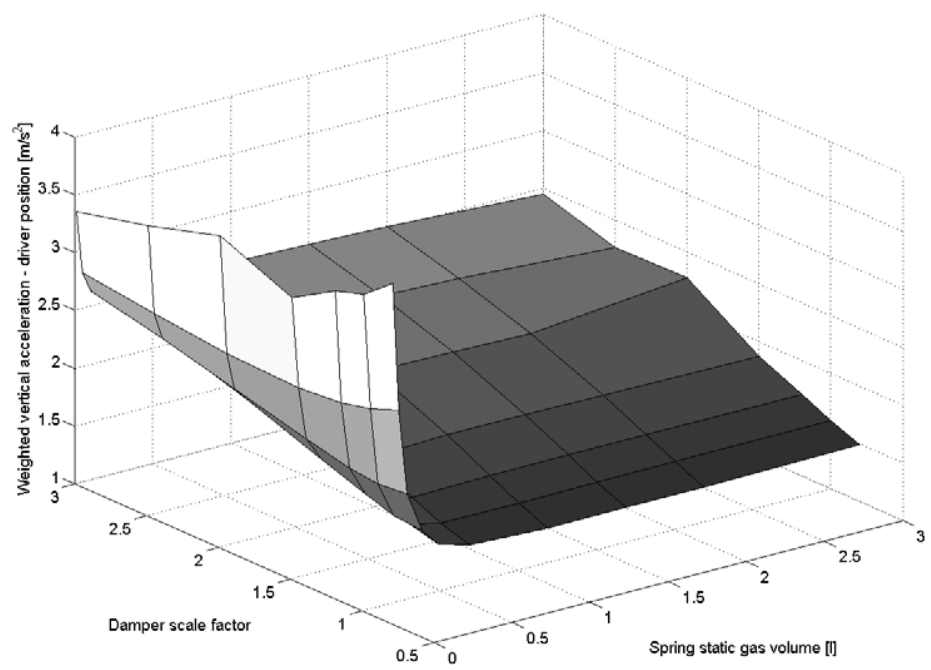

Fig. 7. Results of ride comfort analysis. 
roll angle is achieved with the stiffest spring (static gas volume of 0.1 1) while the roll angle is insensitive to the damper scale factor as could be expected (see Fig. 8). The "best" handling suspension is therefore given by the high-est possible spring stiffness. The areas where there are no data points on the graph are where the vehicle could not complete the lane change without rolling over.

The investigation was further extended by looking at a scenario where ride comfort and handling are simultaneously required. For this analysis, a double lane change was performed over the Belgian paving. The result is indicated in Fig. 9. The infeasible area where the vehicle rolls over is now significantly enlarged. The suspension design is forced towards higher spring stiffness to keep the vehicle safe, at the expense of ride comfort.

It is concluded that for best ride comfort, a soft suspension is needed and for best handling a stiff suspension is needed. For the hard suspension setting, a static gas volume of 0.11 and damping scale factor of between 2 and 3 is suitable and for the soft suspension setting, a gas volume of greater than 0.51 and a damping scale factor of 0.8 will be suitable first order design values. The high damper characteristic used in the design of the suspension system will therefore be between 2 and 3 times the baseline values, while the low damping should be less than 0.8 times the baseline value. This also confirms the results obtained for case study 1 .

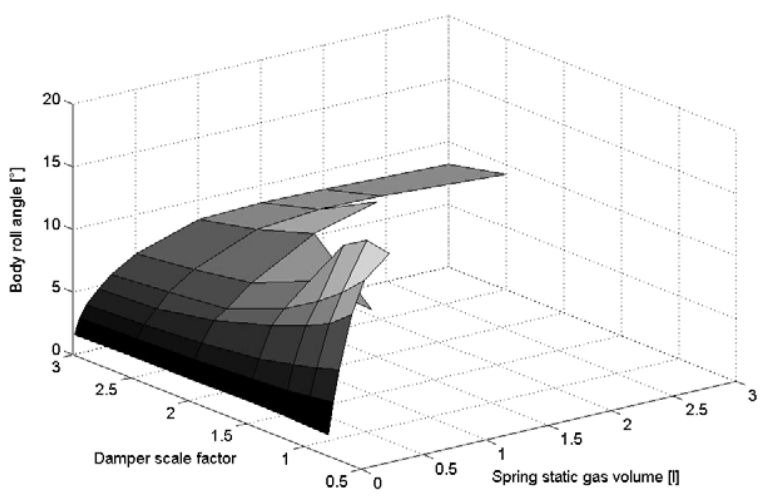

Fig. 8. Results of handling analysis.

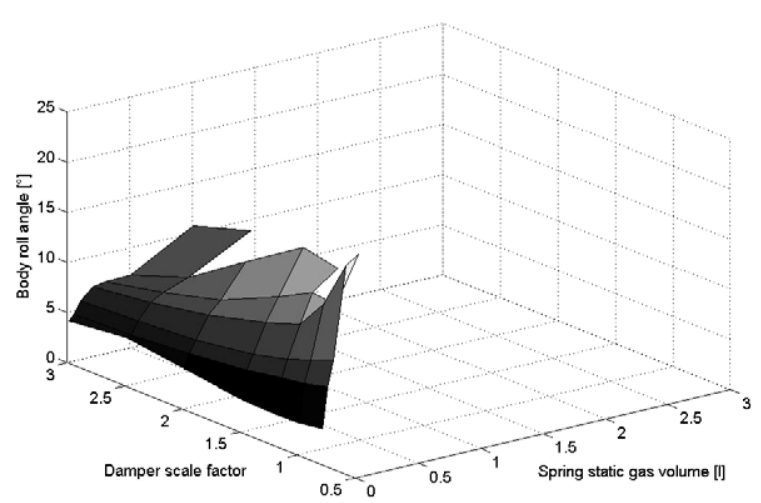

Fig. 9. Combined ride comfort and handling.

\section{Case study 3 - Land Rover Defender 110}

The encouraging results obtained from case study 2 justified the development of an improved vehicle model that could be used to predict absolute values and not only trends as was the case with the first model. The fidelity of this model had to be good enough to accurately predict both ride comfort and handling. This model had to be combined with a model of the controllable suspension system and control system later in the project.

The majority of geometric parameters were obtained by physical measurement on a vehicle, although some critical measurements were obtained from available drawings. Mass properties were obtained from physical measurements on a vehicle. The determination of the centre of gravity position, as well as estimation of the roll, pitch and yaw mass moments of inertia are described by Uys et al. [31]. Spring, damper and bump-stop characteristics were obtained by removing the components from the test vehicle and determining force-displacement and forcevelocity relationships, respectively, using servo hydraulic actuators in displacement control.

Tyre side-force vs. slip angle characteristics were obtained from measurements using a two-wheeled tyre tester towed behind a vehicle. The measured data was converted to the coefficients required for the MSC ADAMS Pacjeka '89 tyre model [32].

Fig. 10 indicates the layout of the front and rear suspension system. The rigid front axle is located longitudinally by leading arms connected to the vehicle body with rubber bushes. The stiffness of these bushes was measured and included in the ADAMS model. Lateral location of the axle is via a Panhard rod. The baseline vehicle is fitted with coil springs, translational dampers concentric with the coil springs and rubber bump stops. A steering angle driver is applied directly to the kingpin with a steering link connecting the left and right wheels. All other steering geometry is ignored in the model. The connections between the different components are indicated in Fig. 11. To take the torsional stiffness of the ladder chassis into account, the

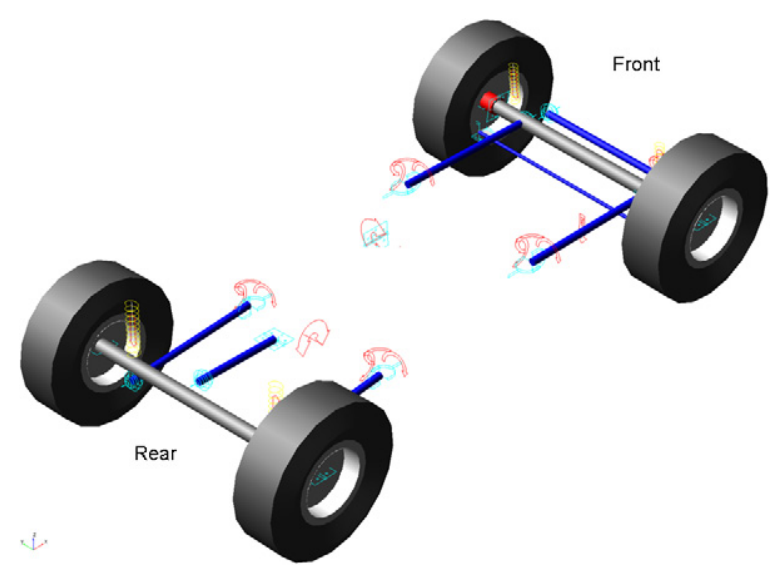

Fig. 10. Suspension layout. 


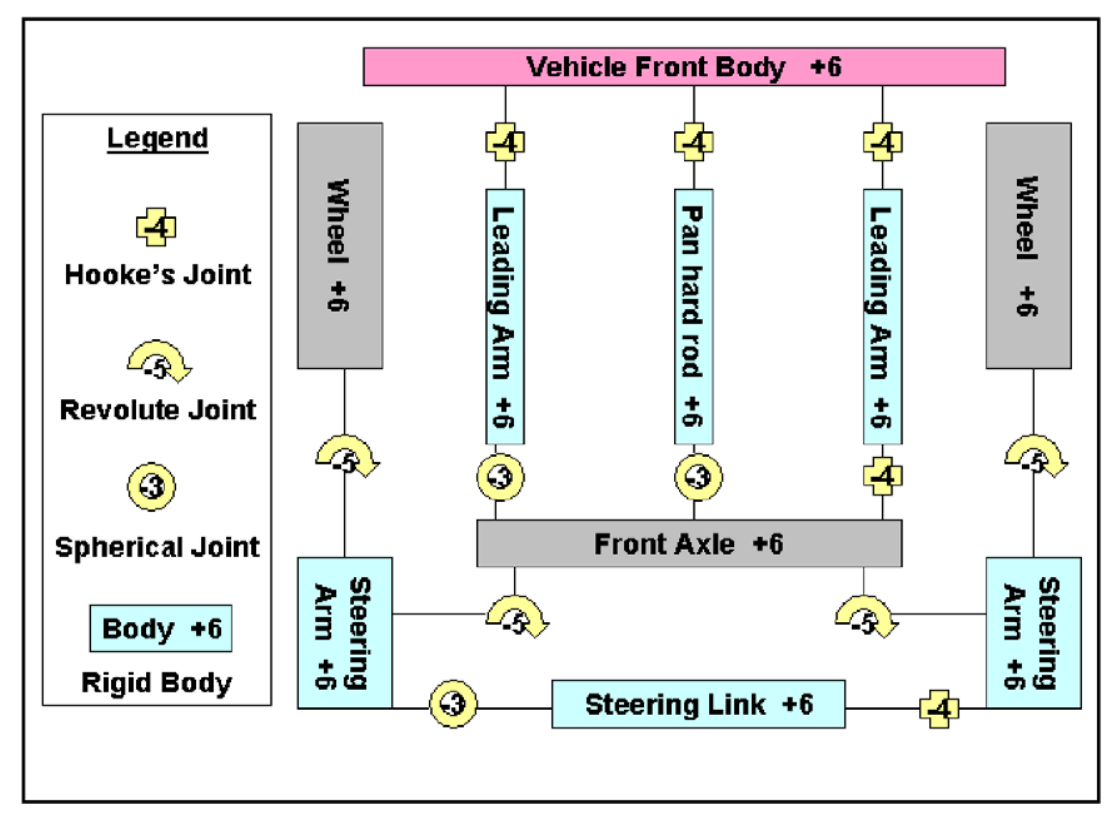

Fig. 11. Front suspension schematic.

vehicle body is modelled as two bodies connected to each other with a revolute joint along the roll axis and a torsional spring.

The rear suspension consists of a rigid axle with trailing arms, an A-arm, coil springs, and translational dampers mounted at an angle outside the coil springs and rubber bump stops. An anti-rollbar, modelled as an equivalent torsional stiffness between the two trailing arms, is fitted to the rear suspension. The stiffness of the trailing arm rubber bushes is included in the ADAMS model. The schematic layout of the rear suspension is indicated in Fig. 12.
A Land Rover Defender 110 SUV was obtained for testing purposes. The aim of the baseline vehicle tests was to validate the ADAMS model of the vehicle. Tests were performed at the Gerotek vehicle test facility [30] West of Pretoria.

The vehicle was evaluated for ride comfort over repeatable test tracks of various roughness's at known, repeatable and representative speeds. Weighted root mean square vertical accelerations were used to quantify ride comfort. Fig. 13 indicates the vehicle on the Belgian paving track during testing. Tests also included a single discrete bump, as indicated in Fig. 14. Vehicle handling was evaluated

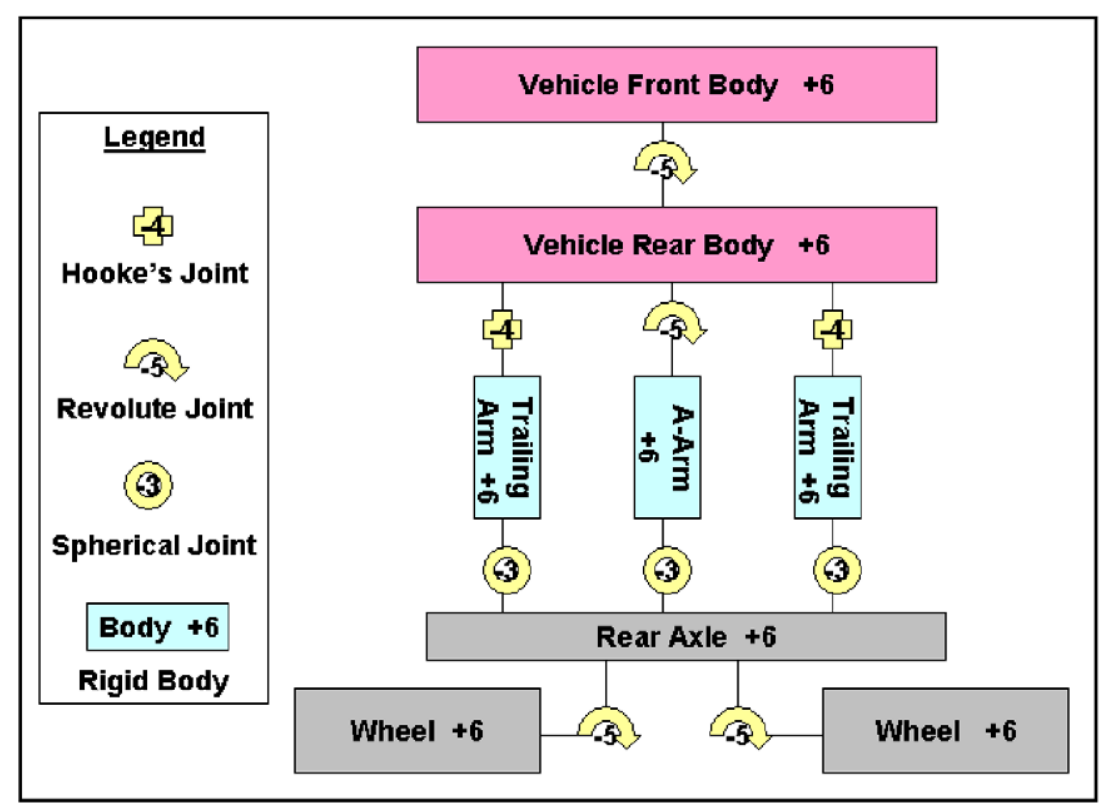

Fig. 12. Rear suspension schematic. 


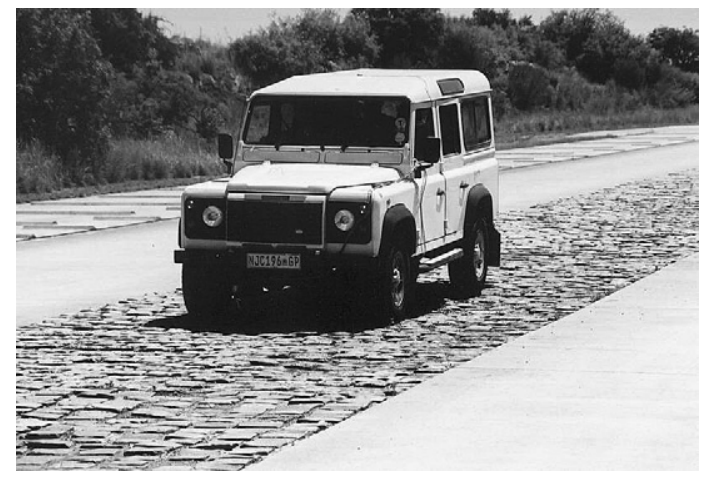

Fig. 13. Belgian paving.

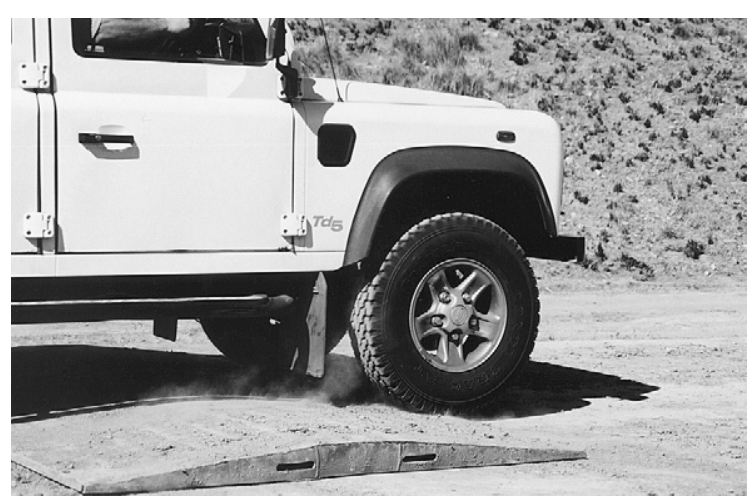

Fig. 14. Single discrete bump.
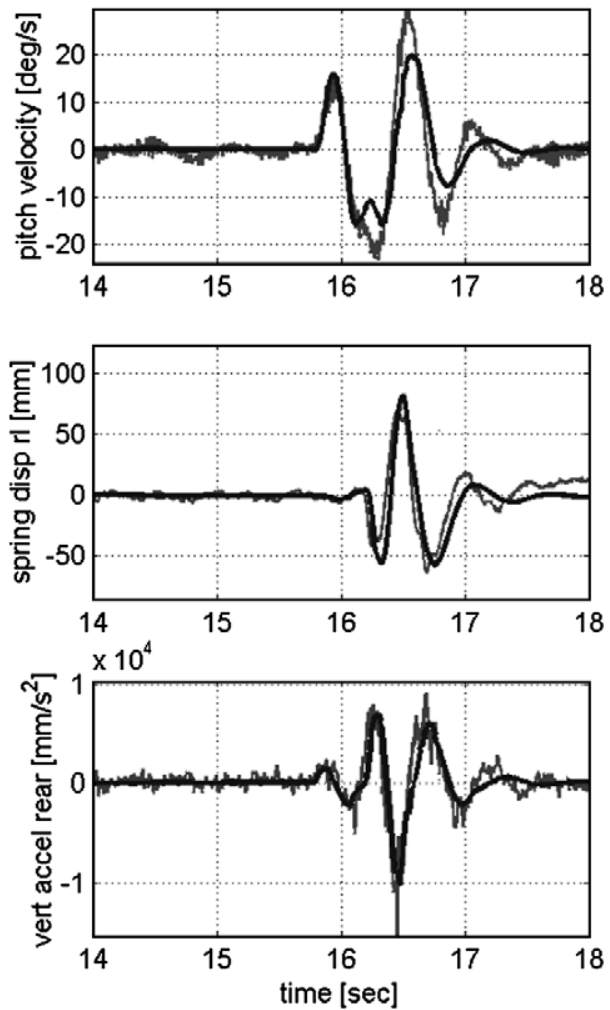

using a constant radius test as well as a severe double lane change manoeuvre.

Additional tests over typical off-road terrain were performed on the Gerotek rough track [30] where a combination of ride comfort and handling is required. The rough track consists of natural terrain features embedded in concrete to give repeatability.

Test procedures and terrains were chosen to ensure repeatability. Vehicle speed was kept constant by driving the diesel engine against its governor. This is important, as the baseline test results will be used later to quantify the improvements offered by the controllable suspension system.

To validate the ADAMS model, simulation results were compared to measured results for two different tests namely the single discrete bump, and the ISO 3888 [10] double lane change test. The bump was chosen to validate the vertical and pitch dynamics of the vehicle. The road input profile is easily measured and included in a simula-tion model. Fig. 15 indicates the correlation obtained between the measured and simulated results for the bump. Correlation is indicated for pitch velocity, spring displacement right front (rf), spring displacement rear left (rl), steering displacement as well as front and rear vertical accelerations. Correlation for vertical accelerations is especially good which is important because vertical acceleration is a direct measure of ride comfort. The model is thus considered validated for ride comfort simulation.
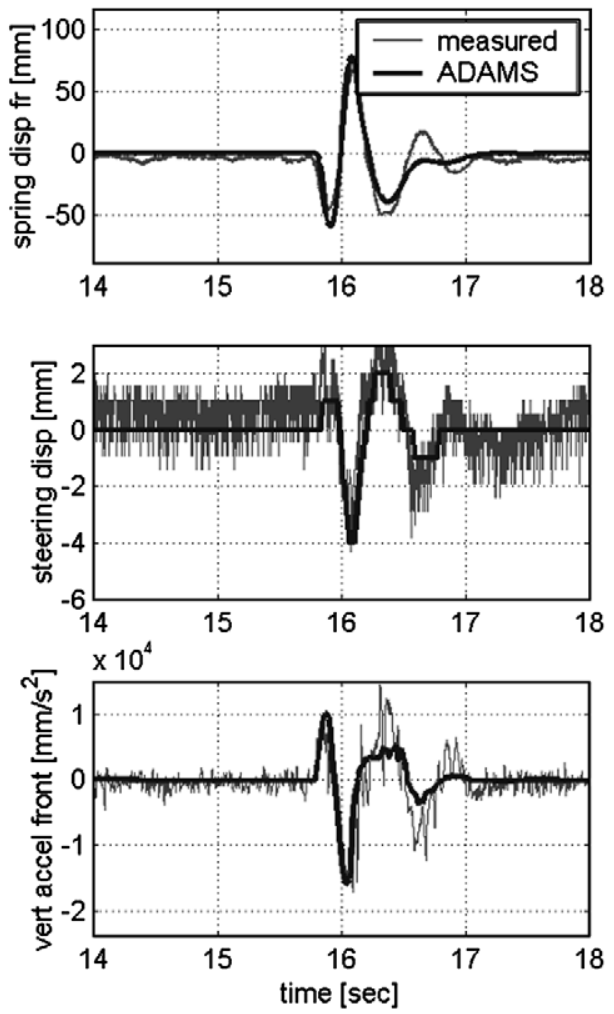

Fig. 15. Model validation results for passing over $100 \mathrm{~mm}$ bump at $25 \mathrm{~km} / \mathrm{h}$. 
Fig. 16 indicates the correlation achieved for a double lane change manoeuvre performed at $65 \mathrm{~km} / \mathrm{h}$. The speed for the baseline vehicle tests varied between 61 and $65 \mathrm{~km} / \mathrm{h}$. The steering input, as measured during baseline testing, was used to drive the vehicle and not the driver model. The graphs therefore represent the dynamic reac- tion of the vehicle to the same input conditions as during testing. Correlation is very good for all the measured parameters. The model is thus considered validated for handling simulation.

The validated ADAMS model was modified by replacing the coil springs with hydropneumatic springs. As before
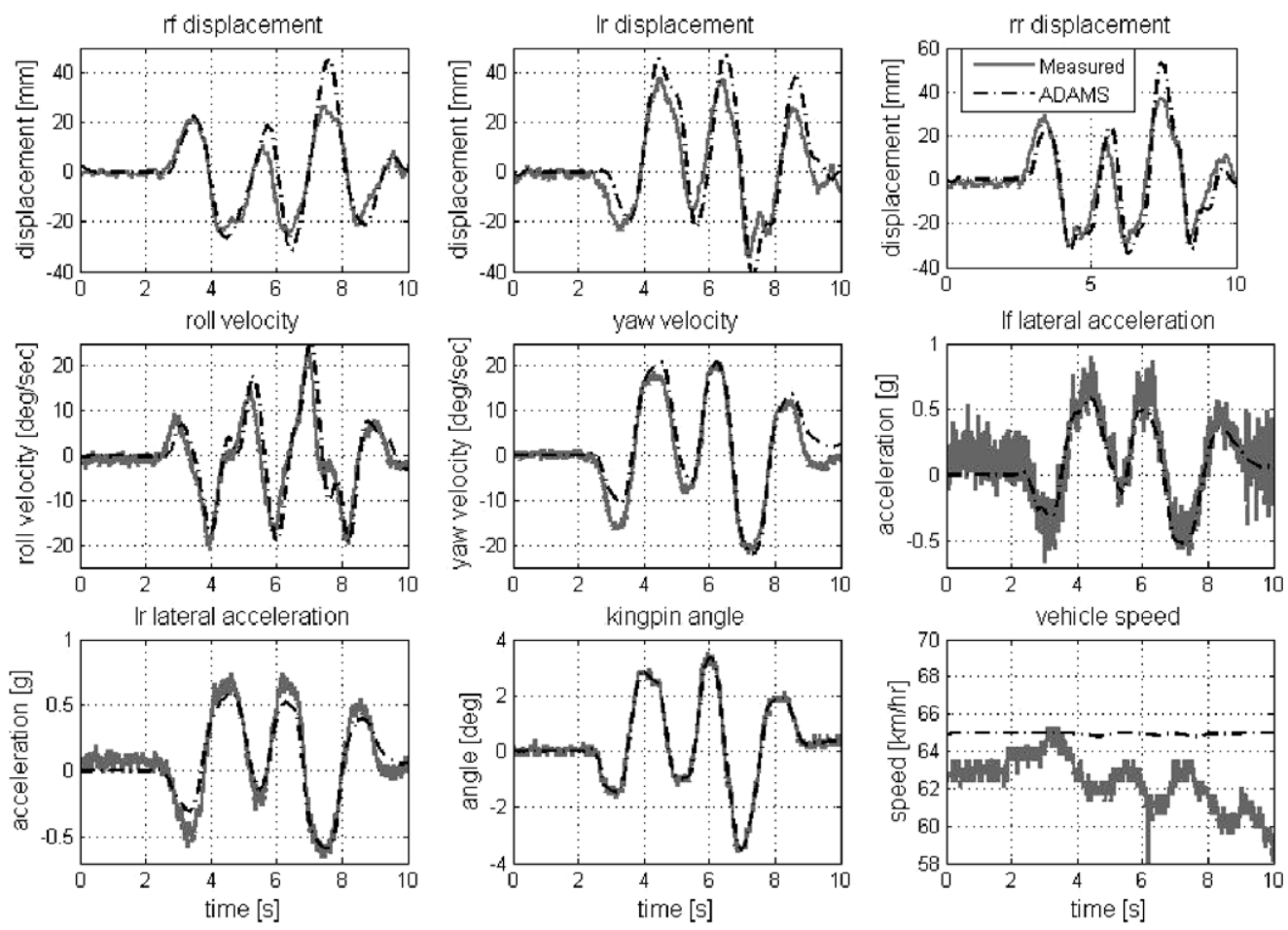

Fig. 16. Model validation results for a double lane change manoeuvre at $65 \mathrm{~km} / \mathrm{h}$.

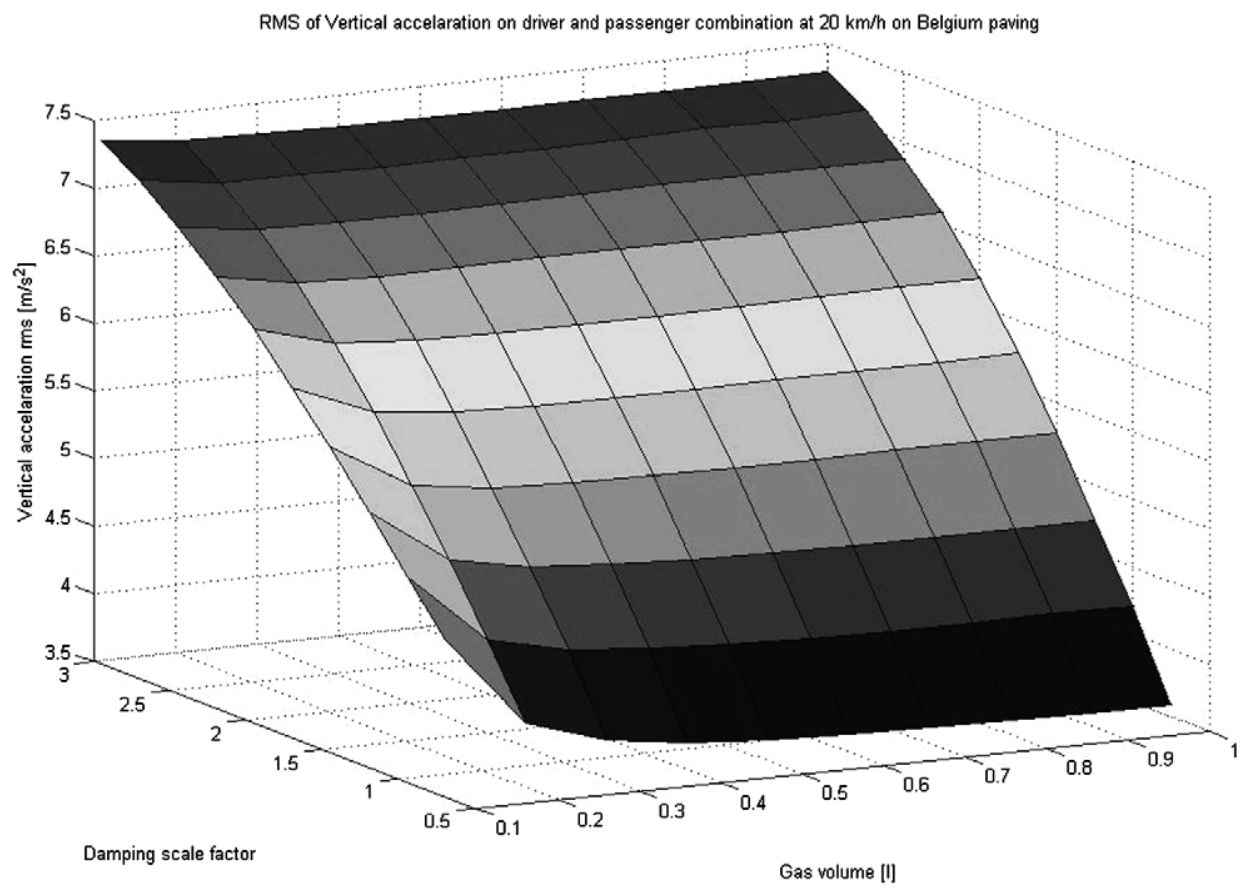

Fig. 17. Ride comfort vs. gas volume and damping. 
the static gas volume was varied between 0.1 and 11 , while the damper scale factor was varied between 0.5 and 3 . The effect of spring and damper characteristics on ride comfort over the Belgian paving is indicated in Fig. 17. The conclusion is made that for best ride comfort, the damping scale factor must be as low as possible and the static gas volume as large as possible although the improvement is negligible for gas volumes higher that 0.51 . For handling, a severe double lane change maneuver was again performed. In this case, both the body roll angle and body roll velocity was used as a measure of handling. Fig. 18 indicates that the maximum body roll angle at the first valley, and maximum roll velocity at the first peak was used. Fig. 19 indicates the maximum roll angle as a function of static gas volume and damper scale factor. The lowest maximum roll angle (best handling) is obtained with a static gas volume of 0.11 and a
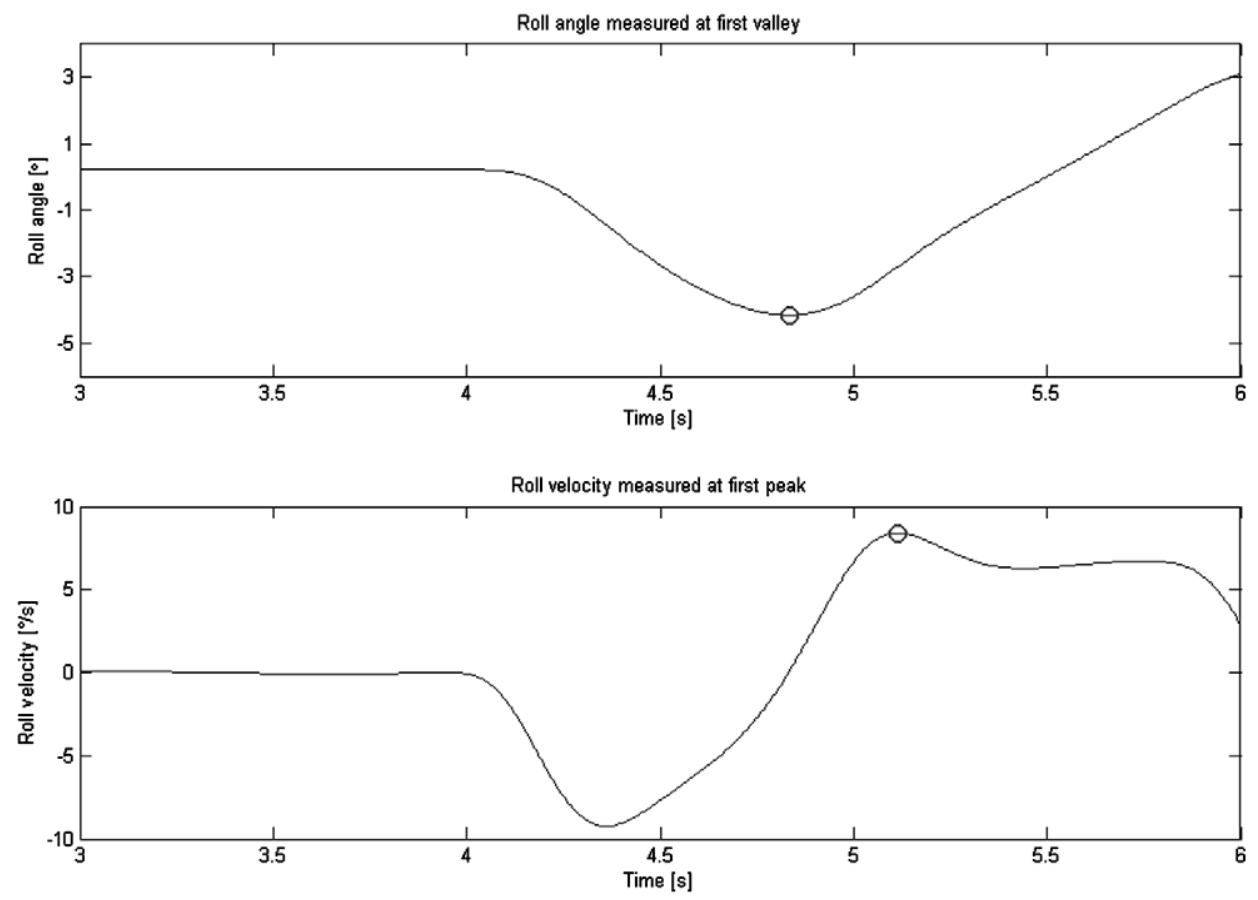

Fig. 18. Definition of handling objective function.

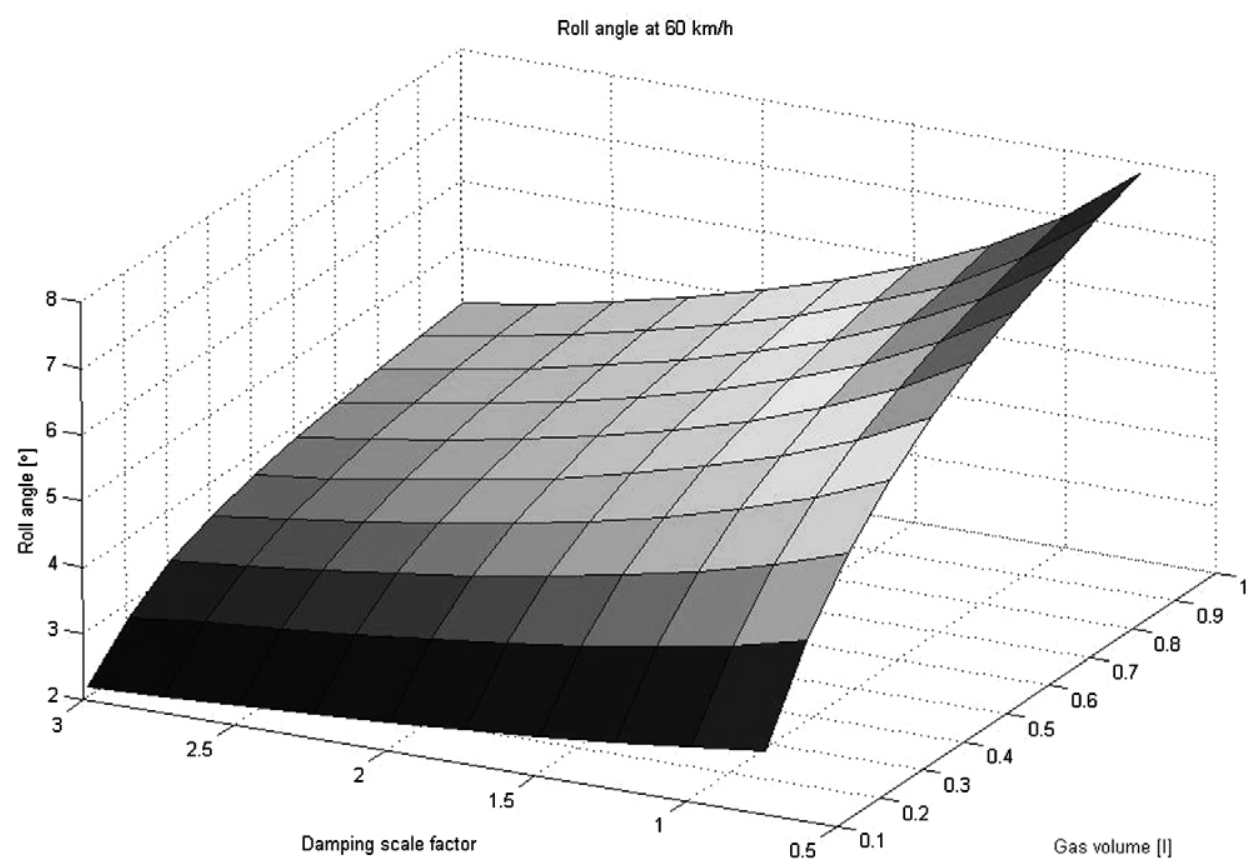

Fig. 19. Roll angle vs. gas volume and damping. 


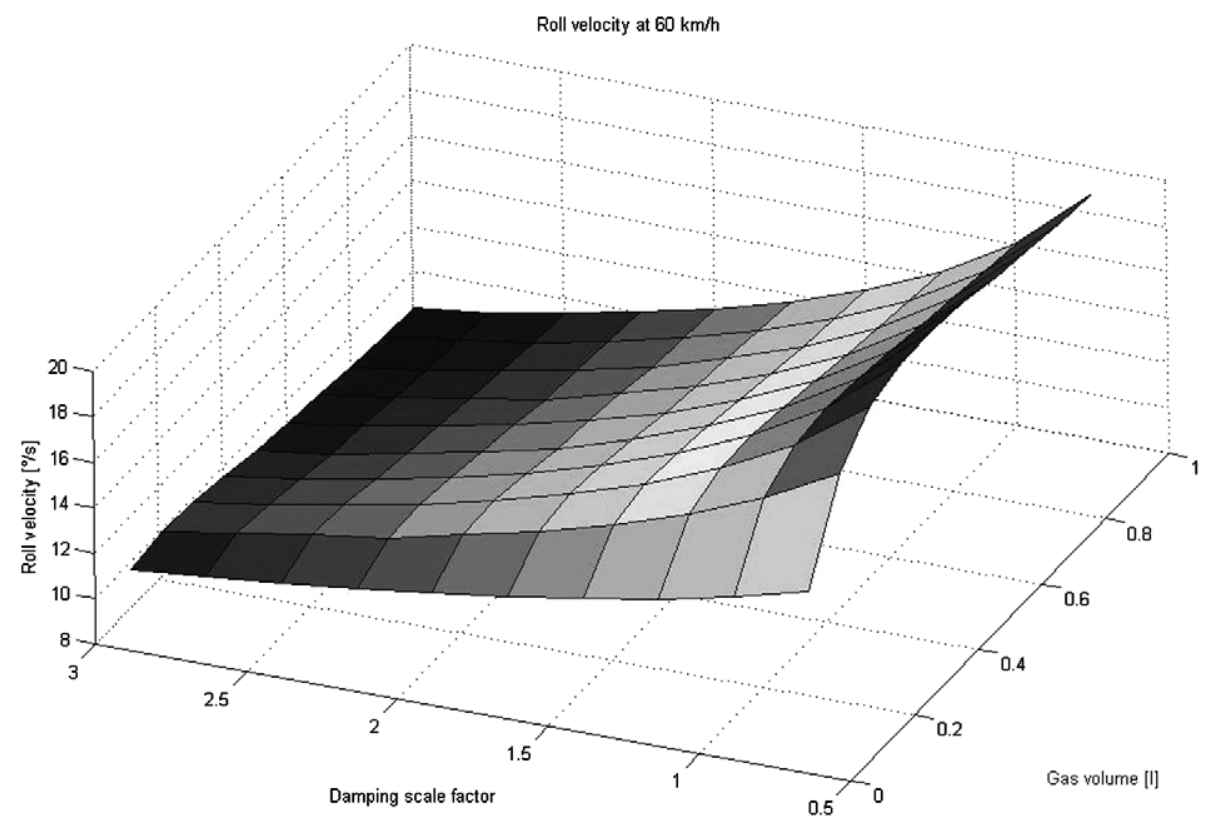

Fig. 20. Roll velocity vs. gas volume and damping.

damper scale factor of 3 . The maximum roll velocity (Fig. 20) is more sensitive to the damper scale factor when compared to the roll angle surface. This result was expected, as damping force is velocity dependant while spring force is displacement dependant. The results however point to a damper scale factor of 3 .

All these results indicate that the optimum characteristics for ride comfort and handling are at opposite corners of the design space. For good ride comfort, low damping and a soft spring is required. A damper scale factor of less than 0.5 and a static gas volume of 0.51 or more will give the best ride comfort. For best handling, a static gas volume of 0.11 and damper scale factor of 3 is required.

\section{Conclusions and future work}

The following is concluded based on the evidence presented in this paper:

(a) A passive suspension system is a compromise between ride comfort and handling as the respective requirements for ride comfort and handling are at opposite ends of the design space. The three-dimensional graphs presented can be used to choose a compromise solution if desired.

(b) The standard way of choosing spring and damper characteristics, is to decide whether to bias the suspension system towards ride comfort, or handling. This compromise is often improved with the use of semi-active dampers and/or ride height control.

(c) A new approach, that seems feasible, is to use a controllable suspension system that can have two discrete states - one giving best possible ride comfort and the other giving best possible handling.
To implement the new approach suggested in (c) above, the following is required:

(a) Two discrete spring characteristics namely:

- A stiff spring for best handling.

- A soft spring for best ride comfort.

(b) Two discrete damper characteristics namely:

- High damping for best handling.

- Low damping for best ride comfort.

(c) The capability to switch between the "ride comfort mode" (soft spring and low damping) and the "handling mode" (stiff spring and high damping).

The evidence presented strongly suggests that a control strategy, which can switch between a "ride comfort" mode and a "handling" mode in a safe and predictable way, should result in significant improvements in both ride comfort and handling. Additional improvements and benefits may be obtained using other combinations of spring and damper characteristics, or applying control to the individual springs and/or dampers, but this will be investigated at a later stage.

The proposed solution to the ride comfort $v s$. handling compromise is to use a twin accumulator hydropneumatic (two-state) spring combined with an on-off (two-state) semi-active hydraulic damper (achieved with a bypass valve), based loosely on an idea by Eberle and Steele [33].

The gas volumes in the two accumulators can be tailored individually to give the two required spring characteristics. Fitting a bypass valve to the damper will enable the damper characteristic to be switched between two 
discrete values. If the damper bypass valve is open, the damper characteristic will be determined by the pressure drop over the valve and associated channels and passages in the valve block. When the bypass valve is closed, the pressure drop over the damper will dictate the characteristics.

Although more than two spring and/or damper characteristics can be incorporated, two is considered sufficient based on the simulation results presented. The pre-requisite is however that a successful ride comfort vs. handling decision-making strategy can be developed that will automatically switch between the "ride comfort" and "handling" modes. The switching must be safe and quick enough to prevent accidents, using only easily measurable parameters.

The proposed suspension system will be referred to as the 4-State Semi-active Suspension System or $4 \mathrm{~S}_{4}$. From the simulation results represented for these case studies, vertical acceleration can be reduced by a factor of two compared to the baseline vehicle using a static gas volume of 0.61 and a damper scale factor of $0.2(20 \%$ of baseline damping). On the other hand, the body roll angle through the double lane change can also be reduced by a factor of two using a static gas volume of 0.11 and a damper scale factor of 2 (double the baseline damping). These represent major improvements in both ride comfort and handling compared to the baseline passive suspension system.

Future work should include the following:

(i) Develop suitable suspension hardware to achieve the required characteristics.

(ii) Develop a control strategy to make the "ride comfort vs. handling" decision.

(iii) Implement on a test vehicle if suspension hardware and control is feasible.

List of abbreviations

AAP average absorbed power

ADAMS automatic dynamic analysis of mechanical systems (computer software)

APG Aberdeen proving ground

BS British standard

DADS dynamic analysis and design system (computer software)

ISO International Standards Organisation

MSC MSC software corporation

NATO North Atlantic Treaty Organisation

NHTSA National Highway Traffic Safety Administration (USA)

NRMM NATO reference mobility model

RMS root mean square

SUV sports utility vehicle

VDI Verein Deutscher Ingenieure (Association of German Engineers)

VDV vibration dose value

\section{Acknowledgements}

The research has been made possible through the generous support and sponsorship of the US Government through its European Research Office of the US Army under Contracts N68171-01-M-5852, N62558-02-M-6372 and N62558-04-P-6004.

\section{References}

[1] International Standards Organisation. Mechanical vibration and shock - evaluation of human exposure to whole-body vibration, part 1: general requirements, ISO 2631-1, 2nd ed. The International Organisation for Standardisation; 15 July 1997.

[2] British Standards Institution. British standard guide to measurement and evaluation of human exposure to whole body mechanical vibration and repeated shock, BS 6841; 1987.

[3] Hohl GH. Ride comfort of off-road vehicles. In: Proceedings of the 8 th international conference of the ISTVS, vol. I of III, Cambridge, England, August 5-11; 1984.

[4] Pradko F, Lee RA. Vibration comfort criteria, SAE Technical Paper 660139. Warrendale: Society of Automotive Engineers; 1966.

[5] Els PS. The applicability of ride comfort standards to off-road vehicles. J Terramech 2005;42:47-64.

[6] Murphy RW. Further development in ride quality. In: Proceedings of the 8th international conference of the ISTVS, vol. I of III. Cambridge, England, August 5-11; 1984.

[7] Harty D. A review of dynamic intervention technologies and a method to choose between them. In: Vehicle dynamics expo 2005, Open technology forum, May 31-June 2, 2005, Stuttgart Messe, Stuttgart, Germany; 2005.

[8] Uys PE, Els PS, Thoresson MJ. Criteria for handling measurement. J Terramech 2006;43:43-67.

[9] Gillespie TD. Fundamentals of vehicle dynamics. Warrendale, PA: Society of Automotive Engineers, Inc.; 1992.

[10] International Standards Organisation. International Standard ISO 3888-1: passenger cars - test track for a severe lane-change manoeuvre - part 1: double lane-change, ISO 3888-1:1999(E); 1999

[11] International Standards Organisation. International Standard ISO 3888-2: passenger cars - test track for a severe lane-change manoeuvre - part 2: obstacle avoidance, ISO 3888-2:2002(E); 2002.

[12] Birch S. Mercedes and the "Moose test". Global Viewpoint Automot Eng Int 1998:11-3.

[13] Garrot WR, Howe JG, Forkenbrock G. Results from NHTSA's experimental examination of selected manoeuvres that may induce on road untripped light vehicle rollover, NHTSA 2001-01-0131; 2001.

[14] International Standards Organisation. International Standard ISO 7401: road vehicles - lateral transient response test methods, ISO 7401:1988(E); 1988.

[15] Els PS, Uys PE. Investigation of the applicability of the dynamic-Q optimisation algorithm to vehicle suspension design. Math Comput Model 2003;37:1029-46.

[16] Choi SB, Lee HK, Chang EG. Field results of a semi-active ER suspension system associated with skyhook controller. Mechatronics 2001;11:345-53.

[17] Data S, Frigero F. Objective evaluation of handling quality. In: Proceedings of the institution of mechanical engineers, vol. 216, part D, J. Automob Eng; 2002. p. 297-305.

[18] Crolla DA, Chen DC, Whitehead JP, Alstead CJ. Vehicle handling assessment using a combined subjective-objective approach, SAE Technical Paper No. 980226; 1998.

[19] National Highway Traffic Safety Administration. Roll over prevention Docket No. NHTSA-2000-6859 RIN 2127-AC64. www.nhtsa.dot.gov/cars/rules/rulings/Rollover/Chapt03.html; 2000 [accessed September 2002]. 
[20] Vlk F. Handling performance of truck-trailer vehicles: a state-of-theart-survey. Int J Vehicle Des 1985;6(3):323-61.

[21] Harty D. Branding vehicle dynamics. Automot Eng Int 2003:53-60.

[22] Karnopp D. Active damping in road vehicle suspension systems. Vehicle Syst Dyn 1983;12:291-316.

[23] Holdmann P, Holle M. Possibilities to improve the ride and handling performance of delivery trucks by modern mechatronic systems. JSAE Rev 1999;20:505-10.

[24] Karnopp D, Margolis D. Adaptive suspension concepts for road vehicles. Vehicle Syst Dyn 1984;13:145-60.

[25] Hine PJ, Pearce PT. A practical intelligent damping system. IMechE 1988;C436/88:141-7.

[26] Wallentowitz H, Holdman P. Hardware and software demands on adjustable shock absorbers for trucks and passenger cars. http:// www.ika.rwth-aachen.de/vortrag/ph-hdt; 1997 [accessed 26.08.97].

[27] Ikenaga S, Lewis FL, Campos J, Davis L. Active suspension control of ground vehicle based on full-vehicle model. In: Proceedings of the American control conference, Chicago, Illinois; June 2000. p. 4019-24.

[28] Nell S. ' $n$ Algemene Strategie vir die Beheer van Semi-Aktiewe Dempers in ' $n$ Voertuigsuspensiestelsel, A general strategy for the control of semi-active dampers in a vehicle suspension system. Unpublished PhD thesis, Department of Mechanical and Aeronautical Engineering, Faculty of Engineering, University of Pretoria; November 1993.

[29] Els PS, Van Niekerk JL. Dynamic modelling of an off-road vehicle for the design of a semi-active, hydropneumatic spring-damper system. In: Proceedings of the 16th international association for vehicle system dynamics (IAVSD) symposium: dynamics of vehicles on roads and tracks, Pretoria, South Africa, August 30- September 3; 1999.

[30] www.gerotek.co.za; 2006 [accessed 19.06.06].

[31] Uys PE, Els PS, Thoresson MJ, Voigt KG, Combrinck WC. Experimental determination of moments of inertia for an off-road vehicle in a regular engineering laboratory. Int $\mathbf{J}$ Mech Eng Educ 2006;34(4).

[32] Bakker E, Pacejka HB, Linder L. A new tire model with an application in vehicle dynamics studies. SAE Technical Paper No. 890087; 1989.

[33] Eberle WR, Steele MM. Investigation of fluidically controlled suspension systems for tracked vehicles - final report, Technical Report No. 12072, TACOM Mobility Systems Laboratory, US Army Tank Automotive Command, Warren, Michigan; September 1975. 